\title{
Prediction of residual shear strength of corroded reinforced concrete beams
}

\author{
Ashhad Imam ${ }^{1} \cdot$ Abul Kalam Azad ${ }^{2}$
}

Received: 2 March 2015/ Accepted: 3 August 2016/Published online: 11 August 2016

(c) The Author(s) 2016. This article is published with open access at Springerlink.com

\begin{abstract}
With the aim of providing experimental data on the shear capacity and behavior of corroded reinforced concrete beams that may help in the development of strength prediction models, the test results of 13 corroded and four un-corroded beams are presented. Corrosion damage was induced by accelerated corrosion induction through impressed current. Test results show that loss of shear strength of beams is mostly attributable to two important damage factors namely, the reduction in stirrups area due to corrosion and the corrosion-induced cracking of concrete cover to stirrups. Based on the test data, a method is proposed to predict the residual shear strength of corroded reinforced concrete beams in which residual shear strength is calculated first by using corrosion-reduced steel area alone, and then it is reduced by a proposed reduction factor, which collectively represents all other applicable corrosion damage factors. The method seems to yield results that are in reasonable agreement with the available test data.
\end{abstract}

Keywords Reinforcement corrosion - Shear strength · Residual strength, Reinforced concrete, Degree of corrosion

Ashhad Imam

ashhad.ce@gmail.com; ashhadimam@rediffmail.com

Abul Kalam Azad

akazad@kfupm.edu.sa

1 Department of Civil and Environmental Engineering, Building 16, Room 130, King Fahd University of Petroleum and Minerals, Dhahran 31261, Kingdom of Saudi Arabia

2 Department of Civil and Environmental Engineering, King Fahd University of Petroleum and Minerals, KFUPM, Box 5058, Dhahran 31261, Kingdom of Saudi Arabia

\section{List of symbols}

$V_{\mathrm{c}} \quad$ Shear strength provided by concrete

$V_{\mathrm{s}} \quad$ Shear strength provided by the shear reinforcement

$I_{\text {app }}$ Applied corrosion current density in $\mathrm{mA} / \mathrm{cm}^{2}$

$J_{\mathrm{r}} \quad$ Corrosion rate in $\mathrm{g} / \mathrm{cm}^{2} /$ year

$I_{\text {corr }}$ Corrosion current density in $\mathrm{mA} / \mathrm{cm}^{2}$

$D \quad$ Original diameter of stirrups in $\mathrm{mm}$

a Metal loss factor

$T \quad$ Corrosion period in year

$D^{\prime} \quad$ Reduced net diameter of corroded stirrups in $\mathrm{mm}$

$V_{\text {exu }}$ Experimental shear capacity of un-corroded beams

$V_{\text {thc }}$ Theoretical shear capacity of corroded beams

$V_{\text {exc }}$ Experimental shear capacity of corroded beams

$V_{\text {thu }}$ Theoretical shear capacity of un-corroded beams

$V_{\mathrm{r}} \quad$ Residual shear strength

$R_{v} \quad$ Proposed strength reduction factor

$P_{\mathrm{r}} \quad$ Metal loss rate or penetration rate

$A_{v} \quad$ Area of stirrups in $\mathrm{mm}^{2}$

$A_{v}^{\prime} \quad$ Reduced area of stirrups in $\mathrm{mm}^{2}$

$P_{\mathrm{u}} \quad$ Failure load

$\gamma_{\text {st }} \quad$ Density of steel

\section{Introduction}

Chloride-induced corrosion of reinforcing bars is one of the major causes of deterioration of reinforced concrete structures, affecting structures' useful service life. Load carrying capacity of a corroding member decreases with corrosion time due to progressive loss of steel area, damage propagation in the form of cracking and eventual spalling of concrete cover, and impairment of bond between steel reinforcement and concrete. As the reduction in load carrying capacity due to reinforcement corrosion 
compromises structural safety, corrosion damage has always been a concern. This has generated much interest in developing analytical approaches to predict residual strength of corroded members that may serve as tools to decide on appropriate course of action to ensure safety.

A significant amount of research deals with various issues reinforcement corrosion related to corrosion process, its initiation and damaging effects including strength reduction and prediction of residual strength of corroded members. The past studies mainly focused on three fronts: flexural behavior and load carrying capacity of corroded members for which references (Cabrera 1996; TorresAcosta and Madrid 2003; Torres-Acosta et al. 2007; Rodriguez et al. 1997; Mangat and Elgarf 1999; Azad et al. 2007,2010 ) are cited only as representative samples of work, bond strength and bond behavior of corroded reinforcing bars (Almusallam et al. 1996; Amleh and Mirza 1999; Azad et al. 2010; Fang et al. 2004; Fu and Chung 1997; Jeppsson and Thelandersson 2003; Jin and Zhao 2001; Lee et al. 2002; Ouglova et al. 2008) and cracking of concrete cover due to corrosion of steel bars (Alonso et al. 1998; Molina et al. 1993; Liu and Weyers 1998; Rasheeduzzafar Al-Saadoun and Al-Gahtani 1992; Vidal et al. 2004; Higgins and Farrow 2006).

Relatively, only a few researchers have studied both theoretically and experimentally the effect of corrosion damage on the shear strength of reinforced concrete members. Hence the main focus of this research was to predict the effect of corrosion on the shear strength of reinforced concrete beams.

Rodriguez et al. (1997) have found that the mode of failure changes from bending to shear after corrosion of the reinforcement in beams and that pitting corrosion of the shear stirrups was the most influencing factor in the reduction of the shear capacity of corroded beams. While Higgins and Farrow (2006) indicates shear-compression failure for the lightly corroded specimens and stirrup fracture for severely corroded beams. Juarez et al. (2011) have observed that moderate and severe levels of deterioration mainly influence the ultimate shear strength. A larger reduction in ultimate shear capacity at higher shear span to effective depth, ald, ratios is shown in $\mathrm{Xu}$ and Niu (2003), which has suggested considering the size effect in future study on shear strength. Zhao et al. (2009) have reviewed the existing studies conducted on shear strength of corroded reinforced concrete beams, proposing an empirical equation to estimate the residual shear strength of corroded reinforced concrete beams.

The past findings clearly indicate that the loss of stirrup areas plays a vital role in the reduction of the shear capacity of reinforced concrete members, in addition to the other influencing factors of corrosion damage. The primary aim of this paper is to present the test results of shear strength of corroded beams to highlight the reduction in shear capacity and to propose an approach for the prediction of residual shear strength using experimental correlation. In the proposed approach, the shear strength is calculated first using ACI 318-08 (2008) code formulas using the reduced stirrup area due to corrosion, and then reducing this value with an experimentally correlated reduction factor to account for all applicable corrosion damage factors including non-uniform corrosion. As it is difficult to capture the effects of all applicable factors, some of which are intricately interconnected, it appears more appealing to seek a reduction factor based on experimental data. The accuracy of the proposed method is tested by comparing results with test data from other researchers.

\section{Experimental program}

The experimental work included the following two design variables: (1) two different beam cross sections, $140 \times 220$ and $150 \times 240 \mathrm{~mm}$, and (2) two different corrosion durations, 6 and 10 days, under slightly varying impressed current. Seventeen reinforced concrete beam specimens were used for testing.

\section{Preparation of specimens}

Rectangular reinforced concrete beam specimens of size $140 \times 220 \times 1150$ and $150 \times 240 \times 1150 \mathrm{~mm}$, whose reinforcement details are shown in Fig. 1, were cast for testing. The difficulty in handling larger size specimens discouraged use of larger size specimens. All beams were designed to fail in shear by providing ample tension reinforcement. The effective bottom concrete cover was $50 \mathrm{~mm}$ (clear cover over stirrups $=32 \mathrm{~mm}$ ) and the side concrete cover to stirrups was $40 \mathrm{~mm}$. The tension reinforcement consisted of a pair of $20 \mathrm{~mm}$ diameter steel bars and the vertical stirrups were of double-legged $8 \mathrm{~mm}$ diameter bars spaced uniformly at $80 \mathrm{~mm}$ centers throughout the length of a beam. The spacing of stirrups was kept below the spacing of $d / 2$ (d being the effective depth of a beam). While the top two $8 \mathrm{~mm}$ diameter longitudinal stirrup-holding bars were epoxy-coated to avoid corrosion, all stirrups were left uncoated so that they would be affected by corrosion along with the tension bars. By allowing the tension bars to corrode along with the stirrups, the practical case in which all bars in a beam are subjected to corrosion was simulated. Two separate lead wires, one connecting all the stirrups and the other connecting the bottom tension bars, were used in each beam for electrical connection to supply current. 
Fig. 1 Reinforcement details of test specimens for Group A and B
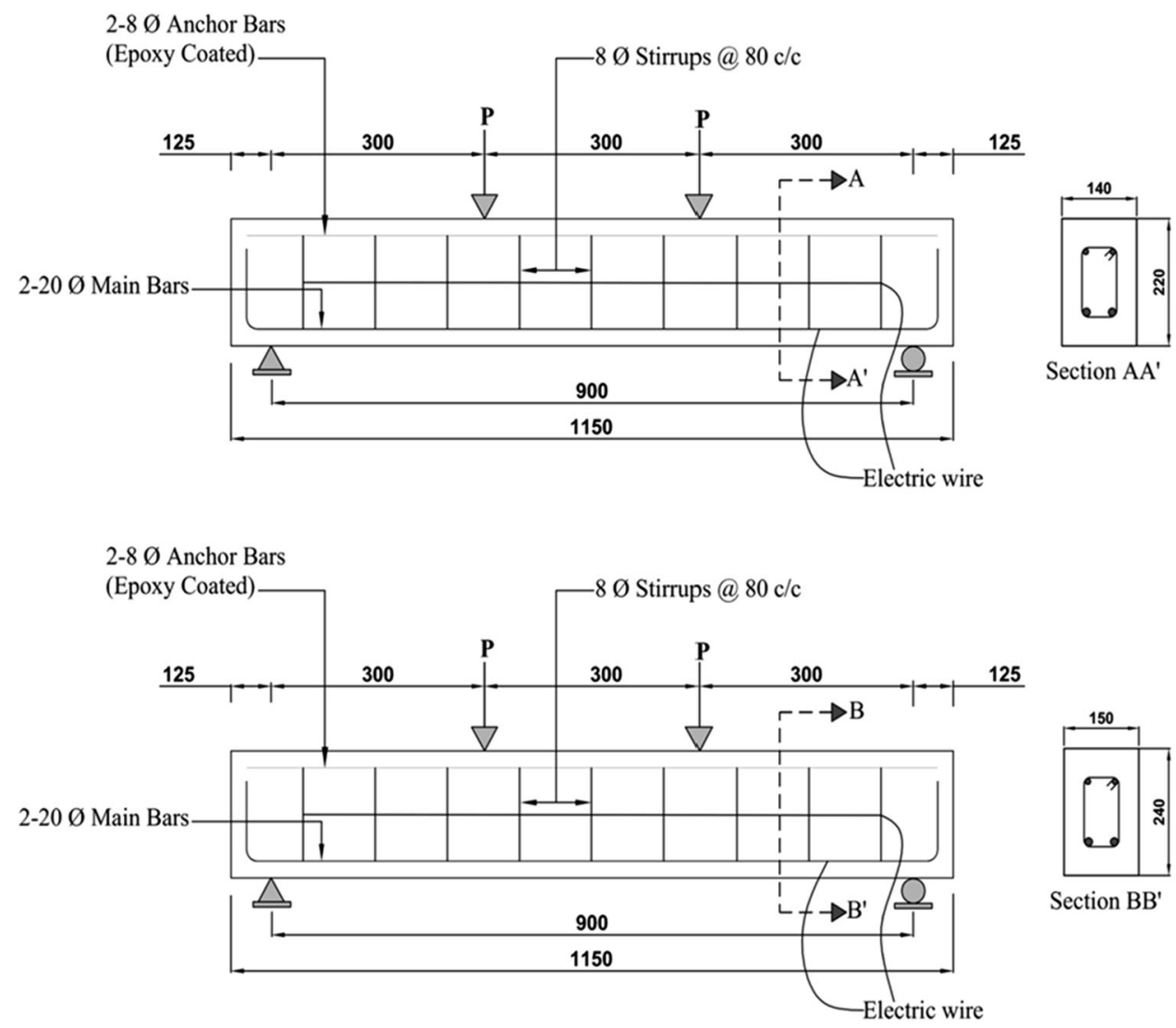

In total, seventeen beams, thirteen corroded and four uncorroded (control) beams were cast. The beams were divided into two groups, Group A having smaller size and Group B comprising larger size. Group A included nine beams, out of which seven were subjected to corrosion. In Group B, out of eight beams, six were earmarked for corrosion. The designation used for corroded beams show the group and the corrosion period (see Table 1). For example, Beam A4-10 implies beam 4 in Group A, which was subjected to corrosion for a period of 10 days.

\section{Materials and proportions}

The mix design used for all specimens consisted of cement content of $370 \mathrm{~kg} / \mathrm{m}^{3}$ (ASTM Type I Portland cement), coarse to fine aggregate ratio of 1.46 (by mass) and watercement ratio of 0.4 (by mass). All specimens were moistcured for 28 days prior to accelerated corrosion induction. In addition to the beams, six cylinders of $75 \times 150 \mathrm{~mm}$ were also cast to determine the average compressive strength of concrete. Two steel coupons were used for tensile testing to determine the average yield strength and ultimate strength of $20 \mathrm{~mm}$ and $8 \mathrm{~mm}$ diameter bars.

The $f_{\mathrm{c}}^{\prime}$ values varied from a maximum of $37.4 \mathrm{MPa}$ to a minimum of $31.5 \mathrm{MPa}$ with a standard deviation of 2.90 . The average 28-days compressive strength of concrete $f_{\mathrm{c}}^{\prime}$ was taken as 33.1 MPa. The target compressive strength $f_{\text {cr }}^{\prime}$ was calculated as $33.3 \mathrm{MPa}$ (based on the relation given by ACI-08) which is almost equal to the average compressive strength taken from the test results.

The reinforcing steel used conformed to ASTM A615/ A615M (2009). For $8 \mathrm{~mm}$ diameter bars (stirrups), yield strength and ultimate strength were 560 and $620 \mathrm{MPa}$, respectively, and for $20 \mathrm{~mm}$ diameter bars (main tension steel), yield strength and ultimate strength were 580 and $700 \mathrm{MPa}$, respectively.

\section{Accelerated corrosion test set-up}

Thirteen beams (seven in Group A and six in Group B listed in Table 1) were subjected to accelerated corrosion by applying anodic current of specified intensity for the chosen duration. The choice of accelerated corrosion was made in view of its wider use in experimental work to reduce the time demand that is normally expected in natural corrosion, and that the accelerated corrosion is viewed as more severe that the natural corrosion in producing corrosion damage. The current was supplied through a DC power source setup that consisted of a rectifier, variable voltage transformer, voltmeter and an ammeter. The concrete specimens were immersed up to a depth of about $160 \mathrm{~mm}$ in $3 \%$ sodium chloride solution in a tank. The direction of the current was 
Table 1 Gravimetric test results and conversion of ight loss into $I_{\text {corr }}$

\begin{tabular}{|c|c|c|c|c|c|c|c|c|}
\hline \multirow[t]{3}{*}{ Beam } & \multicolumn{8}{|c|}{ Conversion of weight loss into $I_{\text {corr }}$} \\
\hline & \multicolumn{6}{|c|}{ Gravimetric test results } & \multirow{2}{*}{$\begin{array}{l}J_{\mathrm{r}} \\
\left(\mathrm{g} / \mathrm{cm}^{2} / \text { year }\right)\end{array}$} & \multirow{2}{*}{$\begin{array}{l}I_{\text {corr }} \\
\left(\mathrm{mA} / \mathrm{cm}^{2}\right)\end{array}$} \\
\hline & $\begin{array}{l}I_{\text {app }} \\
\left(\mathrm{mA} / \mathrm{cm}^{2)}\right.\end{array}$ & $T$ (days) & $\begin{array}{l}\text { Av. length of } \\
\text { stirrups }(\mathrm{cm})\end{array}$ & $\begin{array}{l}\text { Original wt. } \\
\text { of stirrups ( } \mathrm{g} \text { ) }\end{array}$ & $\begin{array}{l}\text { Av. wt. } \\
\text { loss (g) }\end{array}$ & $\begin{array}{l}\rho \% \mathrm{t} . \\
\text { loss }\end{array}$ & & \\
\hline A $1-10$ & 2 & 10 & 55.7 & 201.4 & 57.5 & 28.55 & 14.99 & 1.64 \\
\hline $\mathrm{A} 2-10$ & 2 & 10 & 55.6 & 201.1 & 60.7 & 30.19 & 15.86 & 1.74 \\
\hline A3-10 & 2 & 10 & 55.9 & 202.1 & 78.3 & 38.72 & 20.34 & 2.23 \\
\hline A4-6 & 2 & 6 & 56.0 & 202.6 & 42.4 & 20.93 & 18.33 & 2.01 \\
\hline A5-6 & 2 & 6 & 56.7 & 205.0 & 45.9 & 22.39 & 19.60 & 2.15 \\
\hline A6-6 & 2 & 6 & 55.7 & 201.6 & 39.1 & 19.39 & 16.97 & 1.86 \\
\hline A7-6 & 2 & 6 & 56.5 & 204.2 & 42.9 & 21.03 & 18.41 & 2.02 \\
\hline B1-10 & 2 & 10 & 61.8 & 223.6 & 65.8 & 29.42 & 15.46 & 1.69 \\
\hline B2-10 & 2 & 10 & 62.5 & 225.9 & 60.5 & 26.79 & 14.07 & 1.54 \\
\hline B3-10 & 2 & 10 & 62.5 & 226.2 & 52.3 & 22.98 & 12.09 & 1.33 \\
\hline B4-10 & 2 & 10 & 62.6 & 226.3 & 65.9 & 29.11 & 15.30 & 1.68 \\
\hline B5-6 & 2 & 6 & 62.9 & 227.5 & 38.2 & 16.79 & 14.71 & 1.61 \\
\hline B6-6 & 2 & 6 & 62.5 & 226.3 & 39.0 & 17.23 & 15.09 & 1.65 \\
\hline
\end{tabular}

Fig. 2 Schematic representation of the accelerated corrosion test set-up

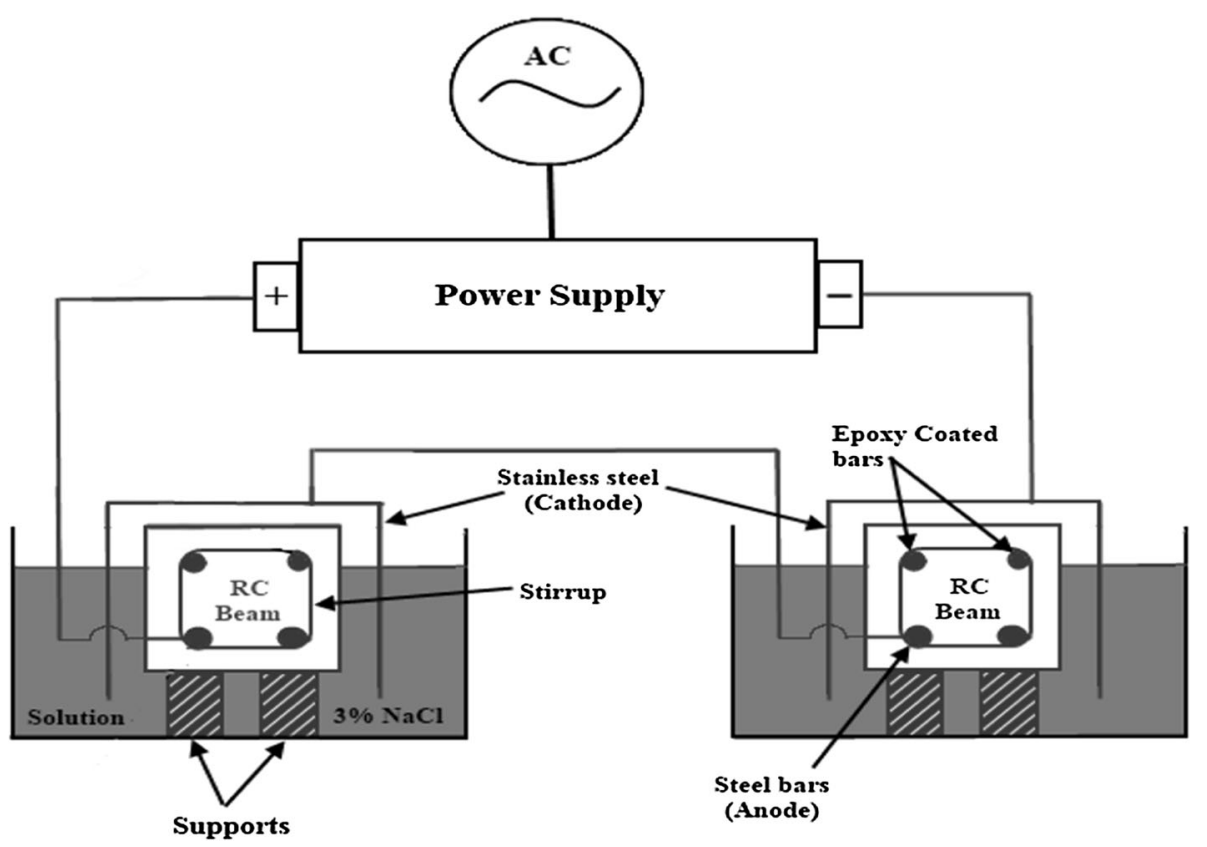

such that the reinforcing steel became anode and the stainless steel plate placed on the concrete specimen as a cathode (see Fig. 2). The total current required for each specimen was calculated on the basis of the total steel surface area, using corrosion current density of $2.0 \mathrm{~mA} / \mathrm{cm}^{2}$. This value is on the higher end of the range used by researchers in accelerated corrosion tests that varied from $0.1 \mathrm{~mA} / \mathrm{cm}^{2}$ (Rodriguez et al. 1997) to $4.0 \mathrm{~mA} / \mathrm{cm}^{2}$ (Mangat and Elgarf 1999). The required current for Group A and Group B specimens were 5.91 and $6.36 \mathrm{~A}$, respectively. The current supplied to each specimen was checked on a regular basis to correct any drift. The corrosion period was chosen as 6 and 10 days to induce low to medium degree of corrosion damage, as in practice extensive damage is not be permitted due to safety reasons.

\section{Testing of specimens}

All beams, corroded and un-corroded, were tested as simply supported beams of $900 \mathrm{~mm}$ span using four-point loading under a universal testing machine. The shear span was kept unchanged at $300 \mathrm{~mm}$ to represent a ratio of shear span to the 
Fig. 3 Setup for four-point bend test

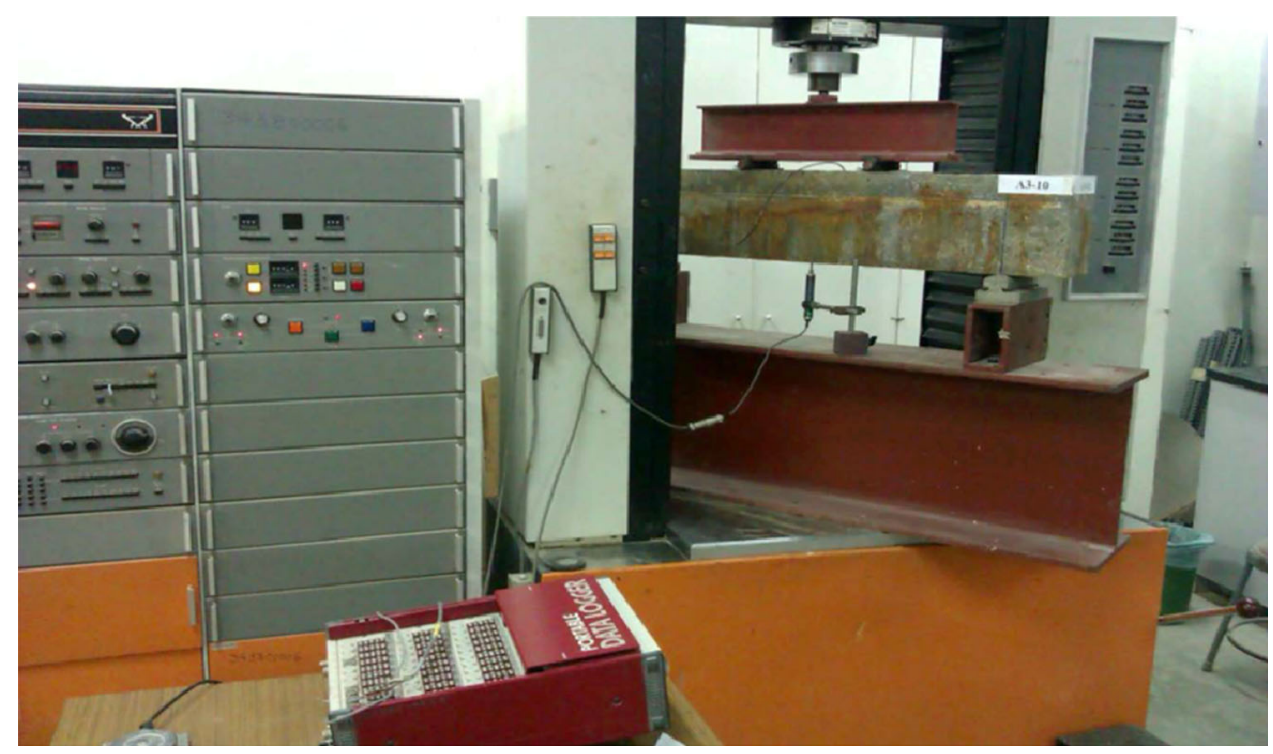

effective depth of a beam more than 1.0 and the loading rate was fixed at $1 \mathrm{~mm} / \mathrm{min}$ (Fig. 1 and 3). Group A specimens had shear span-to-effective depth ratio, a/d $=300 /$ $170=1.76$ and Group B specimens' ald ratio was equal to $300 / 190=1.57$. As the ald ratio was greater than 1.5 but less than 2.0, the beams can be classified as shallow.

The load applied to a beam was increased monotonically until failure. The load and mid-span deflection of each beam were recorded using a computerized data acquisition system along with the failure load and the mode of failure. The load-deflection plot for each tested beam was obtained from the test data.

\section{Gravimetric weight loss analysis}

After testing, each corroded beam was broken to retrieve the corroded stirrups for measurement of the average weight loss of steel due to induced corrosion. Stirrups were cleaned to remove all rust products using Clarke's solution $[1000 \mathrm{ml}$ of hydrochloric acid containing $20 \mathrm{~g}$ antimony trioxide $\left(\mathrm{Sb}_{2} \mathrm{O}_{3}\right)$ and $50 \mathrm{~g}$ stannous chloride $\left.\left(\mathrm{SnCl}_{2}\right)\right]$, and then they were weighed to find the net weight of steel. Preparation, cleaning and evaluation of corrosion test specimens were carried out in accordance with ASTM G-1 (1990). The measured weight loss of steel bars is shown in Table 1 .

\section{Results and discussion}

\section{Weight loss of bars and corrosion current density}

Assuming uniform corrosion, the measured weight loss values were used to calculate the corrosion density $I_{\text {corr }}$ $\left(\mathrm{mA} / \mathrm{cm}^{2}\right)$ as (Ijsseling 1986):
$I_{\text {corr }}=(W / F) / J_{\mathrm{r}}=0.1096 J_{\mathrm{r}}$,

when $J_{\mathrm{r}}=$ corrosion rate in $\mathrm{g} / \mathrm{cm}^{2} /$ year $=$ weight loss $(\mathrm{g}) /$ [(surface area of bar $\left(\mathrm{cm}^{2}\right) \times$ corrosion period (year)], $W=$ equivalent weight of steel $(\mathrm{g})=27.925 \mathrm{~g}$ and $F=$ Faraday's constant $=96487$ Coulombs (A-s).

The calculated values of $I_{\text {corr }}$ are shown collectively for all corroded beams in Table 1. It is noted that identical beams with same $T$ showed some variation in $I_{\text {corr }}$ values determined from weight loss measurements. This is due to the fact that each beam in reality had different resistivity due to small compositional variations that are expected for concrete construction. It is also observed that the equivalent $I_{\text {corr }}$ values obtained from gravimetric analysis are not exactly equal to the applied corrosion current density $I_{\text {app }}$. The difference between $I_{\text {corr }}$ and $I_{\text {app }}$ may be attributed to several factors which include resistivity of concrete provided by the concrete cover, quality of concrete and non uniform corrosion rate along the length of the bars (Auyeung et al. 2000).

\section{Shear capacity of un-corroded beams}

The experimental shear capacity, $V_{\mathrm{exu}}$ of the un-corroded beams of Group A and B (control beams) was determined as $V_{\mathrm{exu}}=P_{\mathrm{u}} \mathrm{kN}$, where $P_{\mathrm{u}}$ is the failure load (the maximum value of $P$ in Fig. 1). The average of the two values of $P_{\mathrm{u}}$ in a group represented the value of shear capacity $V_{\text {exu }}$ for that group. The experimental values of $V_{\text {exu }}$ for Group A and B beams were 140.1 and 148.6 kN, respectively. For comparison, the theoretical shear capacities of un-corroded beams $V_{\text {thu }}$ were calculated in accordance with the ACI 318-08 (2008). 
$V_{\text {thu }}=\left(V_{\mathrm{c}}+V_{\mathrm{s}}\right)=\left[0.17 \sqrt{f_{\mathrm{c}}^{\prime}} b_{\mathrm{w}} d+A_{\mathrm{v}} f_{\mathrm{y}} \frac{d}{s}\right]$

when $V_{\mathrm{c}}=$ shear strength provided by concrete, $V_{\mathrm{s}}=$ shear strength provided by the shear reinforcement, $f_{\mathrm{c}}^{\prime}=$ compressive strength of concrete in $\mathrm{MPa}, b_{\mathrm{w}}$ and $d=$ width and depth of beam, respectively, in $\mathrm{mm}$, $f_{\mathrm{y}}=$ tensile strength of steel in $\mathrm{MPa}$ and $A_{v}=$ area of shear reinforcement in $\mathrm{mm}^{2}$ within the spacing $s$ in $\mathrm{mm}$. The computed values were: for Group $\mathrm{A}, V_{\mathrm{c}}=23.3 \mathrm{kN}$, $V_{\mathrm{s}}=119.5 \mathrm{kN}$ and $V_{\mathrm{thu}}=142.8 \mathrm{kN}$; for Group B beams, $V_{\mathrm{c}}=27.9 \mathrm{kN}, V_{\mathrm{s}}=133.5 \mathrm{kN}$ and $V_{\text {thu }}=161.4 \mathrm{kN}$. The ratio of $V_{\text {exu }} / V_{\text {thu }}, 0.98$ for Group A and 0.92 for Group B indicate that the ACI values appear to yield satisfactory results for the test specimens. For comparison with the shear strength of corroded beams, the experimentally determined values, $V_{\text {exu }}$ and not $V_{\text {thu }}$ values, were considered as the actual strength of the un-corroded control beams.

\section{Shear strength of corroded beams}

The experimentally determined shear capacities of all corroded beams, $V_{\text {exu }}$, are shown in Table 1 for all test specimens. Results show that the shear capacity of corroded beams declined due to corrosion, as expected. For example, Group A beams, which had original shear capacity of $V_{\mathrm{exu}}=140.1 \mathrm{kN}$, the average shear capacity of the three beams, A1-10, A2-10 and A3-10 at corrosion period of $T=10$ days decreased to $87.1 \mathrm{kN}$, about $62 \%$ of the original experimental strength of $140.1 \mathrm{kN}$. For Group B beams at $T=10$ days (B1-10 to B4-10), the average residual strength was about $57 \%$ of the original experimental strength of $148.6 \mathrm{kN}$. The data show significant loss of shear strength of corroded beams for the chosen $I_{\text {corr }}$ and $T$.

As the shear reinforcement provided the bulk of shear resistance for the test beams (over $80 \%$ ), the effect of loss of stirrup area on the shear strength was first examined by calculating the reduced value of $V_{\mathrm{s}}$. The shear capacity of a corroded beam was calculated in the same manner as an un-corroded beam, but using only the reduced diameter of stirrups, $D^{\prime}$ due to corrosion in place of the original diameter, $D$, and ignoring all other applicable crack-induced effects on shear capacity.

Assuming uniform corrosion along the bars, the reduced diameter $D^{\prime}$ is calculated from the well-known formula for metal loss rate or penetration rate, $P_{\mathrm{r}}=J_{\mathrm{r}} / \gamma_{\mathrm{st}}$ (Imam 2012), $\gamma_{\text {st }}$ being density of steel $=7.85 \mathrm{~g} / \mathrm{cm}^{3}$. The reduction in bar diameter in steady-state corrosion current density $I_{\text {corr }}$ for corrosion period $T$ is $2 P_{\mathrm{r}} T$ and the percentage reduction in diameter of bar is $2 P_{\mathrm{r}} T / D \times 100$, where $\mathrm{D}$ is the original bar diameter. From the reduced net diameter of a corroded bar $D^{\prime}=D\left(1-2 P_{\mathrm{r}} T / D\right)$, the reduced cross-sectional area $A_{v}^{\prime}$ of a stirrup is calculated using Eq. (3):

$A_{v}^{\prime}=A_{v}(1-\alpha)^{2}$

where $A_{v}$ is the original cross-sectional area of the shear reinforcement and $\alpha=2 P_{\mathrm{r}} T / D$, which has been termed as 'metal loss factor' in Azad et al. (2007).

Using $A_{v}^{\prime}$ in place of $A_{v}, V_{\text {thc }}$ values of all corroded beams were calculated using ACI 318-08 (2008) in which $V_{\text {thc }}$ equals to the sum of shear strength of concrete $V_{\mathrm{c}}$ and shear strength provided by shear reinforcement, $V_{\mathrm{s}}^{\prime}$ (using reduced area of stirrups). The calculated values of $V_{\text {thc }}$ are presented in Table 2 along with the reduced diameter $D^{\prime}$ and the corresponding values of $R_{\mathrm{f}}$ which is the ratio of $V_{\mathrm{exc}} / V_{\text {thc }}$.

From the data in Table 2, it is observed that the average value of $D^{\prime}$ decreased by more or less than $1.0 \mathrm{~mm}$ from the original diameter of $8 \mathrm{~mm}$, representing reduced crosssectional area of about $76 \%$. $R_{\mathrm{f}}$ values are significantly less than 1.0 , varying from 0.63 to 0.85 . This implies that the residual shear capacity cannot be predicted by using Eq. (2) with the reduced area of shear reinforcement $A_{v}^{\prime}$ alone for moderate corrosion, and, therefore, the effect of other factors must be taken into account in determining the shear capacity.

As the corrosion induced cracking mostly is confined to the concrete cover, the concrete core within the confinement of stirrups remains essentially un-cracked and undamaged and therefore is capable of contributing to the shear strength. Using the reduced width $\mathrm{b}^{\prime}$ (original width $b_{\mathrm{w}}$ minus the clear side covers and the stirrup diameters), the reduced contribution of concrete to shear strength $V_{\mathrm{c}}^{\prime}$ was calculated but no reduction in depth was considered since already an effective depth is adopted for computations. For Group A beams, $V_{\mathrm{c}}^{\prime}=7.3 \mathrm{kN}$, showing a loss of $16.0 \mathrm{kN}$ from the original $V_{\mathrm{c}}$ of $23.3 \mathrm{kN}$ and for Group B beams, $V_{\mathrm{c}}^{\prime}=10.0 \mathrm{kN}$, a reduction of $17.9 \mathrm{kN}$ from the original value of $27.9 \mathrm{kN}$. The combined shear strength is expected to be equal to $V_{\mathrm{c}}^{\prime}+V_{\mathrm{s}}^{\prime}$, ignoring other effects such as for example non-uniform or pitting corrosion. While this reduces the calculated values of $V_{\text {thu }}$ shown in Table 2 (reduction of $16.0 \mathrm{kN}$ for Group A beams and 17.9 $\mathrm{kN}$ for Group B beams), the gap between the calculated and experimentally determined shear strength is still significant for most beams.

The retrieved stirrups from the test beams, after testing, has revealed pitting corrosion which reduces area more at the lower bends of the stirrups. This localized reduction in area due to pitting is perhaps a major factor in the reduction of shear strength provided by the stirrups. As it is difficult 
Table 2 Test data for corroded beams

\begin{tabular}{|c|c|c|c|c|c|c|c|c|}
\hline Beam & $D(\mathrm{~mm})$ & $\alpha$ & $I_{\text {corr }} T\left(\mathrm{~mA}\right.$-year $\left./ \mathrm{cm}^{2}\right)$ & $D^{\prime}(\mathrm{mm})$ & $V_{\text {thc }}(\mathrm{kN})$ & $V_{\text {exc }}(\mathrm{kN})$ & $R_{f}=\frac{V_{\text {exc }}}{V_{\text {thc }}}$ & $\overline{R_{v}(\text { Eq. } 5)}$ \\
\hline A $1-10$ & 8 & 0.131 & 0.045 & 6.95 & 113.5 & 96.1 & 0.85 & 0.69 \\
\hline A2-10 & 8 & 0.138 & 0.048 & 6.89 & 111.9 & 81.6 & 0.73 & 0.68 \\
\hline A3-10 & 8 & 0.178 & 0.061 & 6.58 & 104.1 & 83.5 & 0.80 & 0.62 \\
\hline A4-6 & 8 & 0.096 & 0.033 & 7.23 & 120.9 & 88.5 & 0.73 & 0.74 \\
\hline A5-6 & 8 & 0.103 & 0.035 & 7.18 & 119.5 & 87.6 & 0.73 & 0.73 \\
\hline A6-6 & 8 & 0.089 & 0.031 & 7.29 & 122.5 & 90.0 & 0.73 & 0.76 \\
\hline A7-6 & 8 & 0.096 & 0.033 & 7.22 & 120.6 & 103.0 & 0.85 & 0.74 \\
\hline B1-10 & 8 & 0.135 & 0.046 & 6.92 & 127.8 & 80.9 & 0.63 & 0.69 \\
\hline B2-10 & 8 & 0.123 & 0.042 & 7.02 & 130.6 & 103.0 & 0.79 & 0.70 \\
\hline B3-10 & 8 & 0.105 & 0.036 & 7.16 & 134.8 & 105.0 & 0.78 & 0.73 \\
\hline B4-10 & 8 & 0.133 & 0.046 & 6.93 & 128.1 & 90.0 & 0.70 & 0.69 \\
\hline B5-6 & 8 & 0.077 & 0.026 & 7.38 & 141.5 & 119.1 & 0.84 & 0.78 \\
\hline B6-6 & 8 & 0.079 & 0.027 & 7.37 & 141.2 & 110.0 & 0.78 & 0.78 \\
\hline
\end{tabular}

to predict the reduction in area due to pitting corrosion, unlike uniform corrosion as assumed, and to develop exact mathematical formulations of all applicable corrosion damage factors, it appears an empirical approach that has experimental correlation is perhaps a better option for a strength prediction model.

Numerous variables are always preferred in an experimental program so as to develop a more generalized empirical model which can be applicable in most of the conditions. However, a comprehensive experimental studies may need to be conducted based on the past research data to further explore a coherent results.

\section{Load-deflection plots and mode of failure}

The total applied failure load, $2 P_{\mathrm{u}}$, and the corresponding mid-span deflection for each of the beam specimens were recorded using data logger. Typical load-deflection plot for corroded and un-corroded beam specimens (see Fig. 4) clearly indicate that reinforcement corrosion has a marked influence on the ductility of the beams. The failure of corroded beams indicated brittleness with loss of original ductility. The stiffness of the corroded beams was not influenced so much due to the reinforcement corrosion. The ultimate deflection of the beams, however, decreased with increasing reinforcement corrosion, leading to a reduction in the ductility of the beams.

The damage induced by accelerated corrosion produced finer cracks along the beams that allowed rust products to escape. Some beams developed longitudinal crack near the level of the submerged depth due to corrosion of stirrups (Fig. 5). This is known for accelerated corrosion of specimens in semi-submerged condition due to escape of rust products. All un-corroded beams failed with the development of diagonal shear crack in the shear span at both ends of a beam, the crack advancing from the support and moving towards the load point (Fig. 6). All corroded beams also failed in similar manner (see Figs. 5, 7). The corroded beams show loss of ductility compared with un-corroded beams (Imam 2012). For the degree of corrosion damage induced, no tearing-off failure of corroded stirrups was observed prior to failure of beams.

\section{Estimation of residual shear strength of corroded beams}

\section{Observations}

It is observed that the shear strength of a corroded beam at a given value of $I_{\text {corr }} T$ is affected predominately by the following two factors:

1. The loss of metal due to corrosion. The net crosssectional area of stirrups decreases with the loss of metal and this in turn would reduce the shear capacity of the beam.

2. Crack damage. Because of corrosion-induced cracking, the concrete cover does not fully contribute to shear strength, unlike the core within the confinement of steel which essentially remains un-cracked and undamaged. Of the concrete area $b_{\mathrm{w}} d$, providing the shear resistance $V_{\mathrm{c}}, b_{\mathrm{w}}$ is effected by cracking due to corrosion of stirrups. A better understanding and modeling of cracked concrete for shear strength is still lacking. 
Fig. 4 Typical load deflection plot

Fig. 5 Horizontal corrosion crack in beam B4-10

Fig. 6 Cracking of un-corroded beam $\mathrm{A} 1-\mathrm{C}$ prior to failure
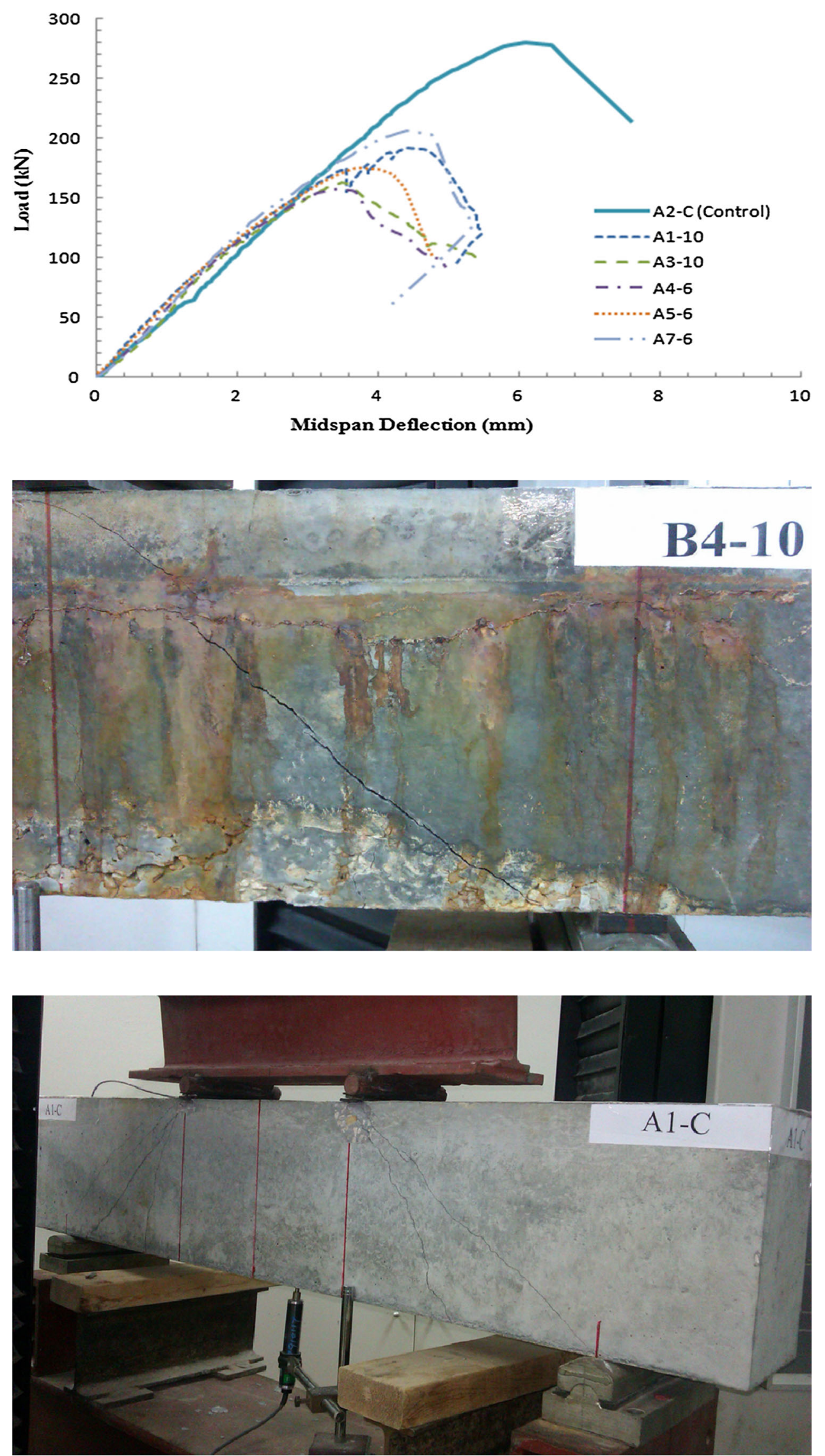
Fig. 7 Cracking of corroded beam A9-6 prior to failure

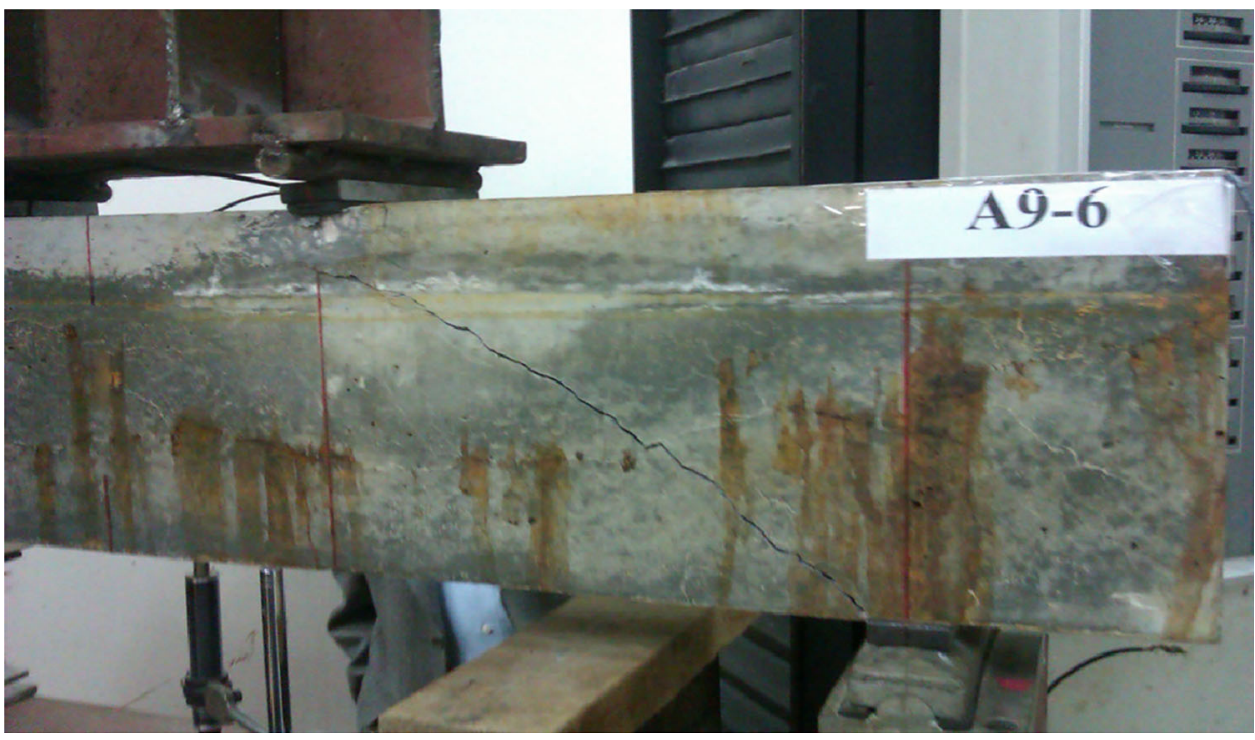

Furthermore, it has been observed that the metal loss is not uniform along the perimeter of stirrups. The metal loss is more acute at the bend of stirrups, indicating pitting corrosion is the common phenomenon. Possible loss of bond may be another factor that requires investigation, though it would appear that for closed stirrups this may not be a critical factor for loss of strength. The major factors for loss of strength are, therefore, the loss of stirrup area and crack damage to side cover coupled with the existence of pitting corrosion. As it is difficult to accurately capture the effects of various damage-related phenomena through analytical models due to intricacies of the problem, it is plausible and perhaps more encouraging to seeking an experimentally correlated factor that collectively and meaningfully represents the adverse effects of corrosion other than the metal loss. This initiative led to the development of a two-step procedure for prediction of residual shear strength, following a similar approach adopted for flexure strength of corroded beams (Azad et al. 2007, 2010). In this approach, first the shear capacity is calculated using Eq. (2) with reduced area of stirrups $A_{v}^{\prime}$. This choice was made to retain the original form of Eq. (2) with the use of full width $b_{\mathrm{w}}$ and not $b^{\prime}$. The calculated value is then corrected by multiplying with a strength reduction factor $R_{v}$ developed through a multi-level regression analysis of test data using the most significant variables.

\section{Reduction factor $R_{v}$}

The proposed value of $R_{v}$ is taken as a function of the two most important variables namely, $I_{\text {corr }} T$ and $A_{v} / \mathrm{d} s$. The first factor takes into account the degree of corrosion and the second factor represents the amount of shear reinforcement as shear reinforcement ratio, which is an important factor in Eq. (2). Although only two values of $A_{v} / \mathrm{d} s$ were used in this limited work, this parameter being an essential factor for computation of shear strength was retained. Thus, $R_{v}$ was taken as a function of $I_{\text {corr }} T$ and $A_{v} / \mathrm{d} s$.

Based on the experimental observations and several trial empirical forms, $R_{v}$ is taken as:

$R_{v}=1-\left\{C\left(I_{\mathrm{corr}} T\right)^{x}\left(A_{v} / \mathrm{d} s\right)^{y}\right\}$

The constants $C, x, y$ were determined through a multilevel regression analysis of test data seeking a better agreement of $V_{\text {thc }}$ values with the experimental values. With the values of $C=4.52, x=0.64$ and $y=0.14, R_{v}$ is given as (Imam 2012):

$R_{v}=1-\left\{4.52\left(I_{\mathrm{corr}} T\right)^{0.64}\left(A_{v} / \mathrm{d} s\right)^{0.14}\right\}$

where: $d=$ depth of beam in $\mathrm{mm}, s=$ spacing of stirrups in $\mathrm{mm}, A_{v}=$ area of stirrups in $\mathrm{mm}^{2}, I_{\text {corr }}=$ corrosion current density in $\mathrm{mA} / \mathrm{cm}^{2}, T=$ duration of corrosion in year. The values of $R_{v}$ for the thirteen corroded beams, calculated using Eq. (4), are shown in Table 2 and they ranged from 0.62 to 0.78 .

It can be seen from Table 2 that the calculated values of $R_{v}$ are in a good agreement with the values of $R_{\mathrm{f}}$ which lends support to the empirical formulation of $R_{v}$. The residual shear strength $V_{\mathrm{r}}$, is then calculated as:

$V_{\mathrm{r}}=R_{v} V_{\mathrm{thc}}$

Although a limited amount of test data forms the basis of the proposed approach for estimation of residual strength, which perhaps can be improved with additional test data, this work highlights the need of such a simplistic approach that can be used in practice. 
Table 3 Comparison of the proposed model results with Rodriguez et al. (1997) data

\begin{tabular}{|c|c|c|c|c|c|c|}
\hline Beam & $T$ (days) & $R_{v}($ Eq. 5) & $V_{\text {thc }}(\mathrm{kN})$ & $V_{\exp }-$ Rodriguez $(\mathrm{kN})$ & $V_{\text {pred }}$ from model $(\mathrm{kN})($ Eq. 6) & $\%$ Error \\
\hline B1 & 104 & 0.80 & 46.8 & 39.8 & 37.5 & 5.9 \\
\hline B2 & 115 & 0.79 & 46.2 & 37.3 & 36.5 & 2.1 \\
\hline B3 & 163 & 0.74 & 43.4 & 27.9 & 32.1 & -15 \\
\hline B4 & 175 & 0.72 & 42.8 & 31.4 & 30.8 & 1.9 \\
\hline B5 & 108 & 0.8 & 47.2 & 34.6 & 37.7 & -8.9 \\
\hline B6 & 116 & 0.79 & 46.7 & 34.5 & 36.9 & -6.9 \\
\hline B7 & 164 & 0.73 & 44.0 & 29.1 & 32.1 & -10.3 \\
\hline B8 & 175 & 0.72 & 43.4 & 33.9 & 31.3 & 7.7 \\
\hline B9 & 108 & 0.80 & 46.6 & 38.6 & 37.3 & 3.4 \\
\hline B10 & 127 & 0.77 & 45.5 & 36.2 & 35.0 & 3.3 \\
\hline B11 & 154 & 0.74 & 43.9 & 26.6 & 32.5 & -22.1 \\
\hline B12 & 181 & 0.72 & 42.5 & 28.7 & 30.6 & -6.6 \\
\hline B13 & 164 & 0.70 & 65.3 & 37.7 & 45.7 & -21.2 \\
\hline
\end{tabular}

The proposed strength prediction model can be utilized either to find the residual shear capacity of a beam that has suffered corrosion damage or to find the maximum corrosion period for a given level of $I_{\text {corr }}$ that can be permitted for a beam at the lowest level of compromised safety. As the empirical method is developed from experimental correlation, it should be recognized that the accuracy of the estimation needs testing in a wider range of $I_{\text {corr }} T$ values. For lower corrosion damage, the method is expected to show reasonable accuracy in prediction. But for practical cases, higher degree of corrosion is expected to occur prior to repair and is not acceptable because of safety concern for which a more comprehensive studies with a large set of data needs to be carried forward and in spite of going for mathematical model, an adaptive tool like Artificial Neural Network (ANN) can be employed to predict the results with higher degree of accuracy and to develop a more generalized model. This can only be achieved with a large number of dataset to better recognize the randomness pattern within the data. With the success of this study, a motivation to further explore the applicability of more advanced Artificial Intelligence (AI) techniques like ANN, Fuzzy Logic, Type-2 Fuzzy Logic, Support Vector Machines and Extreme Learning Machines is enhanced. This study is a contribution to an ongoing effort to develop the application of Artificial Intelligence in solving civil engineering problems.

\section{Comparison of results with the past data}

As it has been mentioned in the previous section that only a few researchers have studied the effect of corrosion damage on the shear strength of reinforced concrete members. In spite of this the results are compared with the data obtained by two researchers to validate the generalization of the developed empirical model. An effort can further be made to conduct more comprehensive comparative studies to make the content more substantial.

The proposed formulation has been checked with available test data of Rodriguez et al. (1997) and Juarez et al. (2011) to verify its accuracy.

\section{Rodriguez et al. data}

Rodriguez et al. (1997) carried out experiments on beams of dimensions $150 \times 200 \times 2300 \mathrm{~mm}$. Compressive strength varied from 34 to $37 \mathrm{MPa}$, and the yield strength of the shear reinforcement was $626 \mathrm{MPa}$. A constant current density of about, $100 \mu \mathrm{A} / \mathrm{cm}^{2}$ was applied to steel bars for a period of time ranging between 100 and 200 days approximately. The details of the comparison are shown in Table 3. It appears from Table 3 that the predicted results from proposed approach are reasonably accurate, as almost $80 \%$ of the data are within the range of $10 \%$ error.

\section{Juarez et al. data}

Juarez et al. (2011) carried out experiments on beams of dimensions $350 \times 200 \times 2000 \mathrm{~mm}$. Compressive strength for the concrete was $21 \mathrm{MPa}$ and the yield strength of the shear reinforcement was $420 \mathrm{MPa}$. A constant current density of $100 \mu \mathrm{A} / \mathrm{cm}^{2}$ was applied to the bars. The duration of current applied to produce a 20 and $50 \%$ loss of shear strength resulting in a moderate and severe level of corrosion was estimated to be 80 and 120 days. The details of the comparison are shown in Table 4. It is noted that with the exception of two cases, the predicted values are in close agreement with the test results, lending confidence in the approach. 
Table 4 Comparison of the proposed model results with Juarez et al. (2011) data

\begin{tabular}{lrllllr}
\hline Beam & $T$ (days) & $R_{v}$ (Eq. 5) & $V_{\text {thc }}(\mathrm{kN})$ & $\begin{array}{l}V_{\text {exp }} \\
\text { Juarez et al. } \\
(\mathrm{kN})\end{array}$ & $\begin{array}{l}V_{\text {pred }} \text { from model } \\
(\mathrm{kN})(\text { Eq. 6) }\end{array}$ & \% Error \\
\hline B1 & 80 & 0.83 & 110.3 & 68 & 92.1 & 35 \\
B2 & 80 & 0.83 & 115.9 & 91 & 96.8 & 6.4 \\
B3 & 120 & 0.78 & 104.9 & 80 & 81.8 & 2.3 \\
B4 & 120 & 0.78 & 114.0 & 86 & 88.9 & 3.4 \\
B5 & 80 & 0.84 & 99.2 & 77 & 83.5 & 8.4 \\
B6 & 80 & 0.84 & 92.7 & 87 & 77.9 & -10.4 \\
B7 & 120 & 0.79 & 92.7 & 80 & 73.2 & -8.5 \\
B8 & 120 & 0.79 & 84.9 & 89 & 68.0 & -23.6 \\
\hline
\end{tabular}

\section{Conclusions}

In this study, thirteen reinforced concrete beam specimens were subjected to accelerated corrosion using impressed current and then they were tested in a four-point bend test to determine their residual shear strength. The following variables were used: two different cross sections of beam and two levels of corrosion period. An approach for estimation of residual strength has been presented. The following conclusions are drawn.

1. The key parameter for the corrosion damage is the corrosion activity index, $I_{\text {corr }} T$. Metal loss, amount of crack-induced damage and the loss of shear strength increase with increasing $I_{\text {corr }} T$.

2. Residual shear capacity cannot be determined simply by using reduced $A_{v}^{\prime}$ alone. The crack induced damage and the occurrence of pitting should be recognized in determining the residual shear strength.

3. Based on the experimental data, an approach has been proposed to predict the residual shear strength of a corroded beam for which $I_{\text {corr }} T$, area of shear reinforcement, spacing of stirrups, cross-sectional details and material strengths are known. The proposed approach consists of determining a reduction factor, $R_{v}$ based on extensive test data with different variables that can be applied to correct the theoretical shear capacity of a corroded beam, calculated on the basis of reduced cross-sectional area, $A_{v}^{\prime}$. This approach appears to produce satisfactory results within the range of $I_{\text {corr }} T$ used in this study.

\footnotetext{
Acknowledgments The authors gratefully acknowledge the financial support provided by the Center of Excellence in Corrosion, Research Institute, King Fahd University of Petroleum and Minerals (KFUPM), Dhahran, Saudi Arabia for this work. The support of the Department of Civil and Environmental Engineering is also acknowledged.
}

Open Access This article is distributed under the terms of the Creative Commons Attribution 4.0 International License (http://crea tivecommons.org/licenses/by/4.0/), which permits unrestricted use, distribution, and reproduction in any medium, provided you give appropriate credit to the original author(s) and the source, provide a link to the Creative Commons license, and indicate if changes were made.

\section{References}

ACI 318-08 (2008) Building code requirements for structural concrete (ACI 318-08) and commentary. American Concrete Institute, Michigan

Almusallam AA, Al-Gahtani AS, Aziz AR, Rasheeduzzafar (1996) Effect of reinforcement corrosion on bond strength. Constr Build Mater 10(2):123-129

Alonso C, Andrade C, Rodriguez J, Diez J (1998) Factors controlling cracking of concrete affected by reinforcement corrosion. Mater Struct 31(7):435-441

Amleh L, Mirza S (1999) Corrosion influence on bond between steel and concrete. ACI Struct J 96(3):415-423

ASTM A615/A615M (2009) Standard specification for deformed and plain carbon steel bars for concrete reinforcement. American Society for Testing and Materials, West Conshohocken

ASTM G-1 (1990) Standard practice for preparing, cleaning and evaluating corrosion test specimens. Annual book of ASTM standards. ASTM Int, Conshohocken

Auyeung Y, Balaguru P, Chung L (2000) Bond behavior of corroded reinforcement bars. ACI Mater J 97(2):214-220

Azad AK, Ahmad S, Azher S (2007) Residual strength of corrosion damaged reinforced concrete beams. ACI Mater J 104(1):40-47

Azad AK, Ahmad S, Al-Gohi B (2010) Flexural strength of corroded reinforced concrete beams. Mag Concr Res 62(6):405-414

Cabrera JG (1996) Deterioration of concrete due to reinforcement steel corrosion. Cement Concr Compos 18(1):47-59

Fang C, Lundgren K, Chen L, Zhu C (2004) Corrosion influence on bond in reinforced concrete. Cem Concr Res 34(11):2159-2167

Fu X, Chung DD (1997) Effect of corrosion on the bond between concrete and steel rebar. Cem Concr Res 27(12):1811-1815

Higgins C, Farrow WC (2006) Tests of reinforced concrete beams with corrosion damaged stirrups. ACI Struct J 103(1):133-141

Ijsseling F (1986) Application of electrochemical methods of corrosion rate determination to system involving corrosion product layers. Br Corros J 21(2):95-101 
Imam A (2012) Shear strength of corroded reinforced concrete beams. M.S Thesis, Department of Civil Engineering, King Fahd University of Petroleum and Minerals, Dhahran

Jeppsson J, Thelandersson S (2003) Behavior of reinforced concrete beams with loss of bond at longitudinal reinforcement. J Struct Eng 129(10):1376-1383

Jin WL, Zhao YX (2001) Effect of corrosion on bond behavior and bending strength of reinforced concrete beams. J Zheijang Univ (SCIENCE) 2(3):298-308

Juarez C, Guevara B, Fajardo G, Castro-Borges P (2011) Ultimate and nominal shear strength in reinforced concrete beams deteriorated by corrosion. Eng Struct 33(12):3189-3196

Lee H, Noguchi T, Tomosawa F (2002) Evaluation of the bond properties between concrete and reinforcement as a function of the degree of reinforcement corrosion. Cem Concr Res 32(8):1313-1318

Liu Y, Weyers R (1998) Modeling the time to corrosion cracking in chloride contaminated reinforced concrete structures. ACI Mater J 95(6):675-681

Mangat P, Elgarf M (1999) Flexural strength of concrete beams with corroding reinforcement. ACI Struct J 96(1):149-158

Molina F, Alonso C, Andrade C (1993) Cover cracking as a function of bar corrosion: part 2-numerical model. Mater Struct 26(9):532-548
Ouglova A, Berthaud Y, Foct F, Francois M, Ragueneau F, PetreLazar I (2008) The influence of corrosion on bond properties between concrete and reinforcement in concrete structures. Mater Struct 41(5):969-980

Rasheeduzzafar Al-Saadoun S, Al-Gahtani A (1992) Corrosion cracking in relation to bar diameter, cover and concrete quality. J Mater Civ Eng ASCE 4(4):327-343

Rodriguez J, Ortega LM, Casal J (1997) Load carrying capacity of concrete structures with corroded reinforcement. Constr Build Mater 11:239-248

Torres-Acosta A, Madrid M (2003) Residual life of corroding reinforced concrete structures in marine environment. J Mater Civ Eng ASCE 15(4):344-353

Torres-Acosta A, Navarro-Gutierrez S, Teran-Guillen J (2007) Residual flexural capacity of corroded reinforced concrete beams. Eng Struct 29(6):1145-1152

Vidal T, Castel A, Francois R (2004) Analyzing crack width to predict corrosion in reinforced concrete. Cem Concr Res 34(1): $165-174$

Xu S, Niu D (2003) The shear behavior of corroded reinforced concrete beams. International Conference on Advances in Concrete and Structures, pp 409-415

Zhao Y, Chen J, Jin W (2009) Design of shear strengths of corroded reinforced concrete beams. Int $\mathrm{J}$ Model Identif Control 7(2):190-198 